\title{
Family Caregivers' Burden of Hemodialysis Elderly Patients at Assiut City
}

\author{
Asmaa B Hassan ${ }^{1}$, Hoda D. F. Ibrahim ${ }^{2}$, Soad A. El H Sharkawy ${ }^{3}$, Hanan A. Abo-Zaid ${ }^{4}$ \\ 1. Nursing Specialist at Technical Nursing Institute, Assiut University, Egypt. \\ 2. Professor of Community Health Nursing, Faculty of Nursing, Assiut University, Egypt. \\ 3. Assistant Professor of Community Health Nursing, Faculty of Nursing, Assiut University, Egypt \\ 4. Lecturer of Gerontological Nursing, Faculty of Nursing, Assiut University, Egypt.
}

\begin{abstract}
Background: One in 10 elderly people worldwide have kidney disease, according to the first detailed global report on care delivery for kidney disease, family caregivers of hemodialysis patients experience high levels of burden. Aim of the study to assess family caregivers' burden of hemodialysis elderly patients Subjects and method: This study included 83 family caregivers were participated in the study. Descriptive research design carried out in the present study for hemodialysis patients' family caregivers within all hemodialysis units at Assiut city. Convenient sample are used in this study by total coverage technique. An interview questionnaire designed by the researchers after reviewed the related literature; it was structured into three parts: Part (1): Care givers personal data and properties, Part (2): Caregivers knowledge about CKD, Part (3):Zarit Sh Caregiver Burden Scale that used to assess caregivers' burden.. Results: Only $1.2 \%$ of caregivers had mild burden\& $71.1 \%$ had severe burden. Conclusion: it is concluded that there was a high percent of studied caregivers had severe burden, also $38.6 \%$ of them had good knowledge. Recommendations: Involving family caregivers counseling and coping mechanisms regarding hemodialysis elderly patients to decrease burden's level.
\end{abstract}

\section{Key words: Hemodialysis, Elderly, Family Caregivers \& Burden.}

\section{Introduction}

The world's elderly population is expected to be 2 billion in the year 2020, most of which will be living in developing countries that can least afford the health care burden encountered by this population group. In Egypt, The Central Agency of Public Mobilization and Statistics (CAPMUS) has reported that elder people in 2016 was around $8.9 \%$, while the expected percentage will be $10.9 \%$ in 2026 . The life expectancy for male elders expected to be 19.3 years in 2026 (CAPMUS, 2016).

The elderly population is the most rapidly growing population segment in the western world. It is estimated that by 2025 , there will be over 800 million individuals over the age of 65 worldwide (Xinhui, et al., 2014).

Chronic kidney disease (CKD) is a global health burden with a high economic cost to health systems and is an independent risk factor for cardiovascular disease (CVD). All stages of CKD are associated with increased risks of cardiovascular morbidity, premature mortality, and/or decreased quality of life. CKD is usually asymptomatic until later stages and accurate prevalence data are lacking. To determine the prevalence of CKD globally, by stage, geographical location, gender and age (Nathan, et al., 2016).

End stage renal disease affects almost all aspects of life of the patients and their caregivers. The caregiver role is stressful and demanding but is often neglected, especially in developing countries. Family caregivers of hemodialysis patients experience high levels of burden. However, these caregivers are often neglected, and no studies are available on the effectiveness of coping strategies on the burden of care among these caregivers (Golnar, et al., 2016).

The significance of the Study

Studies suggest that family caregivers of hemodialysis patients experience a high level of burden, which could lead to numerous physical and psychological problems. Despite the need for adequate training and support, caregivers are mostly neglected, and few studies have been performed in this regard. Caregivers of hemodialysis patients are facing significant burden and more than one third are moderate to severely depressed. Interventions to provide appropriate social support services and improve psychological conditions of caregivers are of urgent and paramount importance (Mansoureh, et al., 2016).

Research Questions

- Do the family caregivers of the hemodialysis elderly patients have caregiving burden?

- Do the family caregivers of hemodialysis elderly patients have lack of knowledge in according to CKD?

The aim of the study: To assess the family caregivers' burden of hemodialysis elderly patients in Assiut city.

\section{Subjects \& Method}

Research design: Descriptive research design was carried out for this study. 
Setting: The study carried out in all hemodialysis units at Assiut city; it is includes: Assiut University Hospital's hemodialysis unit, Health Insurance Hospital's hemodialysis unit, Al- Iman General Hospital's hemodialysis unit, Assiut General Hospital's hemodialysis unit, and Assiut Fever Hospital's hemodialysis unit.

Subjects: The target population of the study are included all family caregivers that attends the hemodialysis unit with their elderly patients in the previous mentioned setting who accept to participate in the study, Which included $\mathbf{8 3}$ family caregivers (23 males and 60 females).

Sample and Sampling: Convenient sample are used in this study. The patients' family caregivers are selected by total coverage technique, according to their participation in the study and had inclusion criteria.

Tool of the study

An interview form for care givers, it was designed by the researcher after reviewed the related literature; it was structured into three parts

Part (1): family Caregivers personal data and properties that included occupation, education, residence, etc.., and their relationship to care recipient that discuss duration of caregiving, household status, financial status, employment status, and transportation.

Part (2): Caregivers knowledge sheet that included closed ended questions about renal functions \& causes, risk factors, symptoms of end stage renal failure, hemodialysis, nutrition of patients, burden's types, sources of burden, and management of burden scoring system for knowledge

- The score of each item summed-up and then converted into percent score (poor $=$ score $<50 \%$, satisfactory $=$ score $50-70 \%$, and good $=$ score $>70$ percentage) (Parvan et al., 2012).

- Part (3): Zarit Sh Caregiver Burden Scale, 22item questionnaire to assess the experience of burden, Likert Scale statement ranged from $(0=$ never, 5= almost always). The necessary modification in the scale was done to be suitable to the study conditions as following:

- Likert Scale statement ranged from (1= never, 3= almost always), it's scoring system as following: it's summed-up and then converted into percent score as following $<50 \%$ indicates little or no burden score between $50-69 \%$ indicates mild to moderate burden, and $70 \%$ and more indicates severe burden (Zarit, et al., 2002).

Validity: The tool was reviewed by 5 experts in the field of nursing science who reviewed the instrument for clarity, relevance, understanding, and applicability.
Reliability: The Cornbrash's alpha coefficient for the instrument was 0.94 with a test-retest reliability of 0.94 .

Methodology:

I- Administrative phase

An official letter approval was obtained from the Dean of the Faculty of Nursing Assiut University to the previous mentioned settings and an official letter approval was obtained from each mentioned setting which includes a permission to carry out the study in the selected hemodialysis units.

\section{II- Ethical considerations}

The research proposal was approved from ethical committee in the faculty of nursing, there is no risk for the study' subjects during the carrying out of the research, participants were advised of their rights to withdraw from the study at any time, participants were coded for data entry so their names couldn't be identified, participant agreement for voluntary participation was obtained and the nature of the study was explained, while confidentiality anonymity was assured.

Pilot study

Pilot study was carried out before starting data collection on 10 percent from the elderly and their caregivers. It aimed to test the clarity of the tools and to estimate the required time to fill the questionnaire, and the pilot study was included in the study.

\section{Field work}

The researcher started to collect data from started at the first of September to the end of November, 2017. After obtaining approval for conducting the research study, the researchers referred to the dialysis unit in every previous mentioned hospital setting and all the patients' family caregivers were selected. Afterwards, the researcher contacted the caregivers to assess their eligibility and give details about the aim of the study. The interview occurred at hemodialysis unit or in the hall area according to hospital facilities in every previous mentioned setting in Asyut city. Each interview took about (30-40) minutes to fill the questionnaire. Every day from 1 to 4 interviews of forms finished, interviews done at morning, and afternoon shifts.

\section{Statistical analysis and scoring system}

The obtained data reviewed, prepared for computer entry, coded, analyzed, and tabulated. Categorical variables were described by number and percent. All analyses were performed with the IBM SPSS 20.0 software version. 


\section{Results}

Table (1): socio demographic characteristics distribution of studied family care givers of hemodialysis elderly patients, Assuit city' hospitals, 2017 (No. 83).

\begin{tabular}{|c|c|c|}
\hline Items of Personal characteristics & $\mathrm{No}=83$ & $\%$ \\
\hline \multicolumn{3}{|l|}{ Age } \\
\hline $18-<35$ years & 50 & 64.0 \\
\hline $35-<50$ years & 20 & 24.0 \\
\hline 50 and more & 10 & 12.0 \\
\hline \multicolumn{3}{|c|}{ Range ( 18 years -69 years) } \\
\hline $\begin{array}{l}\text { Gender } \\
\text { Male }\end{array}$ & 23 & 27.7 \\
\hline Female & 60 & 72.3 \\
\hline $\begin{array}{l}\text { Marital Status } \\
\text { Single }\end{array}$ & 20 & 24.1 \\
\hline Married & 59 & 71.1 \\
\hline Divorced & 2 & 2.4 \\
\hline Widowed & 2 & 2.4 \\
\hline $\begin{array}{l}\text { Level of Education } \\
\text { Illiterate }\end{array}$ & 3 & 3.6 \\
\hline Write and read & 9 & 10.8 \\
\hline Basic education & 50 & 60.2 \\
\hline Secondary education & 3 & 3.6 \\
\hline University & 18 & 21.7 \\
\hline $\begin{array}{l}\text { Occupation } \\
\text { Housewife }\end{array}$ & 29 & 35.0 \\
\hline Free work & 29 & 35.0 \\
\hline Employee & 25 & 30.0 \\
\hline $\begin{array}{l}\text { Residence } \\
\text { Rural }\end{array}$ & 38 & 45.8 \\
\hline Urban & 45 & 54.2 \\
\hline
\end{tabular}

Table (2): The degree of consanguinity of studies family care givers with the studied hemodialysis elderly, at Assuit city' hospitals, 2017 (No. 83).

\begin{tabular}{|l|l|l|}
\hline Degree of consanguinity & No= 83 & \% \\
\hline Husband /Wife & 28 & 33.7 \\
\hline Son / Daughter & 36 & 43.4 \\
\hline Brother/ sister & 2 & 2.4 \\
\hline Other family members & 17 & 22.5 \\
\hline
\end{tabular}

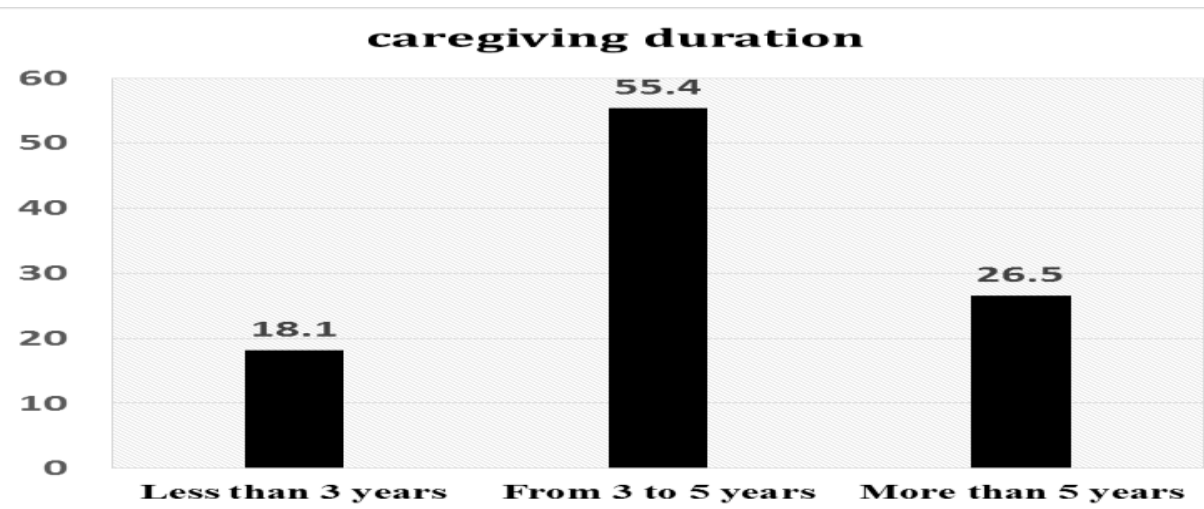

Figure (1): Distribution of studied caregivers regarding caregiving duration of their elderly patients. 
Table (3): total score of knowledge among studied family caregivers about Chronic Kidney Disease of hemodialysis elderly patients, at Assuit city hospital, $2017(\mathrm{No}=83)$.

\begin{tabular}{|l|c|c|}
\hline \multicolumn{1}{|c|}{ Score of knowledge (Knowledge level) } & No= 83 & \% \\
\hline Poor $\leq \mathbf{5 0 \%}$ & 25 & 30.1 \\
\hline Good 51\%-70\% & 32 & 38.6 \\
\hline Very good to Excellent $\geq \mathbf{7 1 \%}$ & 26 & 31.3 \\
\hline
\end{tabular}

Table (4): caregivers' knowledge about caregivers'adaptation methods with burden of hemodialysis elderly patients, at Assuit city' hospitals, 2017 (No=83).

\begin{tabular}{|l|l|l|}
\hline \multicolumn{2}{|c|}{ Item of knowledge } & \multicolumn{2}{|c|}{} \\
\hline Negative Burden' adaptation methods \# & No & $\%$ \\
1) Smoking & 20 & 24.1 \\
\hline 2) Over eating & 17 & 20.5 \\
\hline 3) Waste time in front of the TV or computer & 51 & 61.4 \\
\hline 4) Withdrawal from friends, family, activities & 24 & 28.9 \\
\hline 5) Use medicines to relax & 22 & 26.5 \\
\hline 6) Sleep too much & 31 & 37.3 \\
\hline 7) procrastination & 56 & 67.5 \\
\hline 8) projection (by violent attackand physical violence) & 41 & 49.4 \\
\hline
\end{tabular}

\# More than one answer

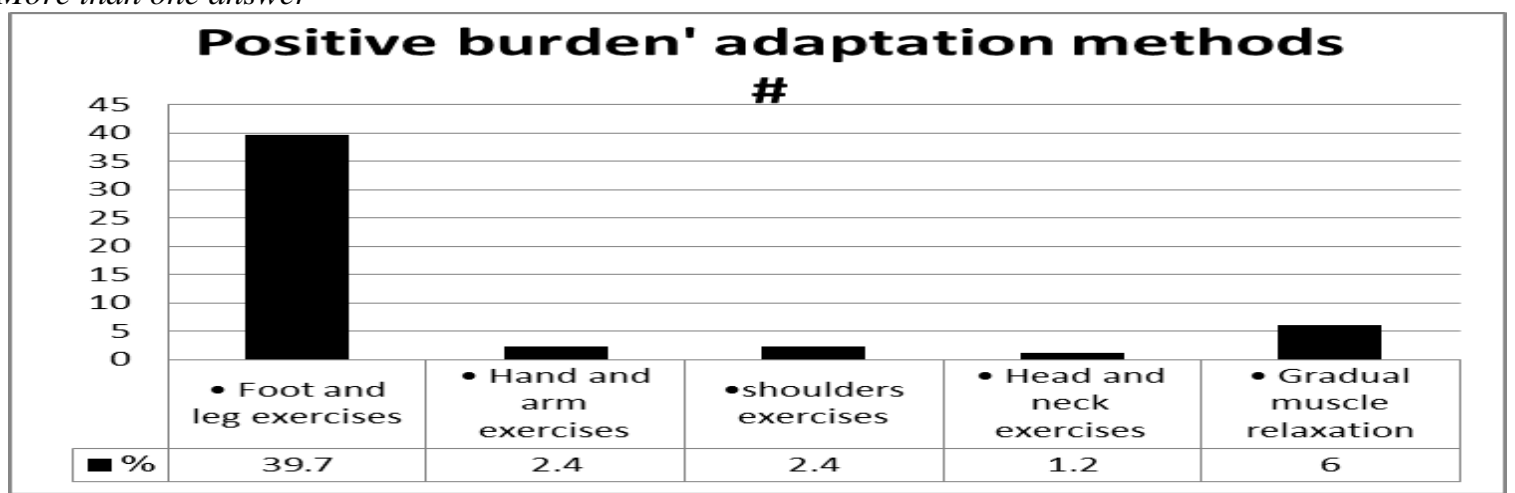

Figure (2): distribution of positive methods that caregivers used to cope with burden at Assuit city, 2017

Table (5): Distribution of studied family caregivers as regard to total care giver burden, at Assuit city' hospitals, 2017 (No. = 83).

\begin{tabular}{|l|l|l|}
\hline \multicolumn{1}{|c|}{ Caregivers' burden } & \multicolumn{1}{c|}{ No } & \multicolumn{1}{c|}{ \% } \\
\hline Little or no burden & 1 & 1.2 \\
\hline Mild to Moderate & 23 & 27.7 \\
\hline Severe & 59 & 71.1 \\
\hline
\end{tabular}


Table (6): Relationship between total caregivers' burden and socio-demographic characteristics of the studied family caregivers of hemodialysis elderly patients, at Assuit' Hospitals, 2017(No= 83).

\begin{tabular}{|l|c|c|c|c|c|c|c|}
\hline \multirow{2}{*}{\begin{tabular}{c}
\multirow{2}{*}{$\begin{array}{c}\text { Socio-demographic } \\
\text { characteristics }\end{array}$} \\
\cline { 2 - 8 }
\end{tabular}} & \multicolumn{6}{c|}{ Little or no burden } & \multicolumn{2}{c|}{$\begin{array}{c}\text { Mild / } \\
\text { Moderate }\end{array}$} & \multicolumn{2}{c|}{ Severe } & \multirow{2}{*}{ p- value } \\
\cline { 2 - 8 } & No & \% & No & \% & No & \% & \\
\hline $\begin{array}{l}\text { Gender } \\
\text { Male }\end{array}$ & 1 & 1.2 & 9 & 10.8 & 13 & 15.7 & \\
\hline Female & 0 & 0.0 & 14 & 16.9 & 46 & 55.4 & 0.080 \\
\hline $\begin{array}{l}\text { Marital Status } \\
\text { Single }\end{array}$ & 0 & 0.0 & 7 & 8.4 & 13 & 15.7 & \\
\hline Married & 1 & 1.2 & 15 & 18.0 & 43 & 51.8 & 0.890 \\
\hline Divorced & 0 & 0.0 & 1 & 1.2 & 1 & 1.2 & \\
\hline Widowed & 0 & 0.0 & 0 & 0.0 & 2 & 2.4 & \\
\hline $\begin{array}{l}\text { Education level } \\
\text { Illiterate }\end{array}$ & 0 & 0.0 & 0 & 0.0 & 3 & 3.6 & \\
\hline Write and read & 0 & 0.0 & 3 & 3.6 & 6 & 7.2 & \\
\hline Basic education & 0 & 0.0 & 11 & 13.2 & 39 & 47.0 & 0.847 \\
\hline Sec. education & 0 & 0.0 & 3 & 3.6 & 0 & 0.0 & \\
\hline University & 1 & 1.2 & 6 & 7.2 & 11 & 13.2 & \\
\hline $\begin{array}{l}\text { Occupation } \\
\text { Housewife }\end{array}$ & 0 & 0.0 & 1 & 1.2 & 28 & 33.7 & \\
\hline Free work & 0 & 0.0 & 11 & 13.2 & 18 & 21.6 & 0.639 \\
\hline Employee & 1 & 1.2 & 11 & 13.2 & 13 & 15.7 & \\
\hline $\begin{array}{l}\text { Residence } \\
\text { Rural }\end{array}$ & 1 & 1.2 & 11 & 13.2 & 26 & 31.3 & \\
\hline Urban & 0 & 0.0 & 12 & 14.5 & 33 & 39.7 & 0.524 \\
\hline
\end{tabular}

Chi-square test, *statistically significance difference ( $p<0.05$ )

Table (1): Shows the sociodemographic data characteristics of the studied family care givers were found that, the average age of them was ranged from 18 to 69 and more years old, while Mean \pm SD of age was $41.37 \pm 12.76$, in which $35.0 \%$ of them were house wife and $72.3 \%, 71.1 \%$ were females and married respectively.

Table (2): Show consanguinity degree of the studied family care givers with the elderly, in which $43.4 \&$ 33.7 of the studied caregivers were sons /daughter\& Husband / Wife of the studied elderly respectively.

Figure (1): Illustrate that $55.4 \%$ of the studied family caregivers had caregiving since 3-5 years ago toward their studied elderly, in which 26.5 of them had caregiving since 5 years ago.

Table (3): Illustrate the knowledge of studied family caregivers regarding to roles of caregivers, in which $84.3 \%, 74.7 \%$ provide medication /physiotherapy \&Provide psychological support to adapt to the disease.

Table (4): Shows negative adaptation methods that $61.4 \%, 67.5 \%$ of caregivers used to waste time in front of $\mathrm{TV}$ and computer and use procrastination as negative adaptation methods, respectively.
Regarded to positive adaptation methods, figure (2) illustrate that $39.7 \% \& 6.0 \%$ of caregivers used foot /leg exercise \& gradual muscle relaxation, respectively.

Table (5): Shows that only $1.2 \%$ of caregivers had mild to moderate burden $\& 71.1 \%$ had severe burden.

Table (6): Shows that $55.4 \%, 51.8 \% \& 39.7 \%$ of the studied caregivers were females, married, and from the urban area had a severe burden. There was no statistically significant difference in according to socio-demographic characteristics and the burden of studied family caregivers.

\section{Discussion}

According to the literature, family caregivers play a pivotal role in the care of patients and are under tremendous physical and psychological pressure. In east culture, it is supposed that women, by their very nature, should give birth, do housework, serve the husband, and grandparents (Bahar, et al., 2013) the finding of the present study revealed that the age average of the studied family care givers was ranged from 18 to 69 while Mean \pm SD of age was $41.37 \pm 12.76$, and more years old, in which one third 
of them were house wife and less than three quarter were females and married.

The current results was agreed with (Adel \& Abdul Manaf, 2012) who conduct a study about Quality of Life of Caregivers and Patients Undergoing Haemodialysis at Ministry of Health, Jordan, in which the majority of the studied caregivers had the same characteristics that mentioned.

In addition, the present study presented that less than half of the studied family caregivers were son or daughter, according to American Sociological Association (ASA). "Daughters provide as much elderly parent care as they can), the current study was in the same line with (Adel \& Abdul Manaf, 2012) found that more than half of the studied family caregivers were son or daughter.

In the present study the researcher was investigated the burden of the caregivers of hemodialysis patients and reported that about three quarter of these family care givers experienced severe burden, this results in the line with (Farahani, et al., 2016) who conducted a study about Effect of Educational Program on the Burden of Family Caregivers of Hemodialysis Patients.

According to total caregivers burden the finding in the present study clear that little more than one quarter of the studied caregivers showed mild to moderate burden, While Mansoureh, et al., (2016) who conducted a study in Iran about Effect of Educational Program on the Burden of Family Caregivers of Hemodialysis Patients who reported that about one tenth of the studied caregivers experienced mild to moderate burden and the majority of them experience sever burden

The findings of this study give insight into the difficulties of providing adequate care for patients with a chronic disease such as End Stage Renal Disease. The aspects that arose from current data analysis indicated that there was a considerable amount of psychosocial and physical burden that had an impact on various aspects of caregiver's wellbeing, in which the majority of the studied caregivers had psychological \& physical burden

In the same line with current study a study that conducted by (Alnazly \& Samara, 2014) about The Burden On Caregivers Of Patients Above 65 Years Old Receiving Hemodialysis: A Qualitative Study, Amman, Jordan who reported that the majority of the studied caregivers had psychological \& physical burden. This was agreed with (Hassan, 2017) who reported that the majority of the studied caregivers had psychological, financial, and physical burden.

\section{Conclusion \& Recommendation}

Based on the results of the present study, it can be concluded that

In consider of burden level of caregivers, more than two third of the studied caregivers had sever burden, and more than half of females and married caregivers had sever burden.

\section{Recommendation}

Involving family caregivers counseling and coping mechanisms regarding care for hemodialysis elderly patients to decrease burden's level.

\section{References}

1. Adel, E., \& Abdul Manaf, M., (2012): Quality of Life of Caregivers and Patients Undergoing Haemodialysis at Ministry of Health, Jordan, January 2012, International Journal of Applied Science and Technology Vol. 2 No. 3; March 2012.

2. Alnazly E., \& Samara N., (2014): The Burden On Caregivers Of Patients Above 65 Years Old Receiving Hemodialysis: A Qualitative Study, Health Care Current Reviews 2:118. doi:10.4172/hccr.1000118.

3. Bahar G., Demirci, A., Siren S., (2018): Factors Influencing Hemoglobin Variability and Its Association with Mortality in Hemodialysis Patients, Scientific World Journal Volume 2018, Article ID 8065691, 7 pages.

4. Bayoumi, M., (2014): Subjective burden on family carers of hemodialysis patients. Open Journal of Nephrology, 4:79-85.

5. Central Agency of Public Mobilization and Statistics (CAPMUS), (2016): prevalence of Egyptian Elderly profile, https://www.acl.gov/.

6. Diane L., (2014): Elmore The Impact of Caregiving on Physical and Mental Health: Implications for Research ,Practice, Education, and Policy p 22. End of Life Clin In_est Med 2013; 36 (3): E121-E126. Vol 36, no 3, June.

7. Farahani, M., Ghane, G., Naime S., Hamid H., (2016): Effect of Educational Program on the Burden of Family Caregivers of Hemodialysis Patients: Evidence Based Care Journal 2016 06:07 originally published online 01 April 2016.

8. Golnar Ghane, Mansoureh Ashghali Farahani, Naima Seyedfatemi, and Hamid Haghani (2016): Effectiveness of ProblemFocused Coping Strategies on the Burden on Caregivers of Hemodialysis Patients, January $02,5(2)$. 
9. Halabi J., (2004): Psychometric properties of the Arabic version of Quality of Life Index. J Adv Nurs. 2006 Sep;55(5):604-10.

10. Hassan Bin Usman Shah, (2017): Caregiver Burden for Patients Receiving Dialysis, Journal of the Pakistan Medical Association 67(10):1498-1501 - January 2017 with 59 Reads

11. Mansoureh A., Ghane G., Naime S., Hamid H., (2016): Effect of Educational Program on the Burden of Family Caregivers of Hemodialysis Patients, Article 1, Volume 6, Issue 1, Spring 2016, Page 7-18, Evidence Based Care Jornal.

12. Mollaoglu, M., Kayataş, M., \& Yurugen, B., (2013): Effects on caregiver burden of education related to home care in patients undergoing hemodialysis. Hemodial Int, 17(3):413-420

13. Nathan R., "* Samuel T., Fatoba, Jason L., Oke, J., Hirst, Christopher A., O'Callaghan, Daniel S., Lasserson, \& F., Richard Hobbs (2016): Global Prevalence of Chronic Kidney Disease - A Systematic Review and MetaAnalysis 2016; 11(7): e0158765.

14. Parvan Kobra, Zamanzadeh Vahid \& Hosseini Fahimeh Alsadat, (2012): Nursing students' perspectives on professional values in the universities of medical sciences in Iran, International Research Journal of Applied and Basic Sciences. Vol., 3 (6), 1183-1191, 2012 Journal for Nurses in Staff Development. 15(5) pp 185-192.

15. Xinhui Wang 1., Joseph V., Bonventre \& Alan R., Parrish (2014): International Journal of Molecular Sciences ISSN 1422-0067 www.mdpi.com/journal/ijms Int. J. Mol. Sci., 15, 15358-15376; doi:10.3390/ijms150915358.

16. Zarit, S., (2002). Concepts and measures in family caregiving research. Paper presented at the Invitational Conference on Family Caregiving,Research, Toronto, Ontario, Canada. 